\title{
Holistic healing through education - a preventive approach
}

\begin{abstract}
Synopsis
Holistic healing bypasses the 'band-aid fix' approach of conventional medicine, looks beyond a person's physical state and sees the holistic view of their state of being or functioning. It acknowledges that the root cause of a physical illness may in fact be non- physical. Numerous works till date validate a deep rooted emotional or psychological issue as a locus of many dreaded physical diseases. Where can the earliest intervention be made? An Exploratory study was taken up to piece together the available data on various scientific studies on the role of epigenetic factors in the causation of disease and the factors determining the health. A suggestive conclusion was made that Positive health is natural. An early intervention via education can equip every individual to a choice of healthy life.
\end{abstract}

Keywords: prevention, holistic health, cellular memory, education
Volume 3 Issue 4 - 2017

\author{
Sapna Sharma \\ Department of Psychotherapy, Frankfinn Institute, India
}

Correspondence: Sapna Sharma, Department of

Psychotherapy, Frankfinn Institute, India,

Email sapna@thespiritualcounseling.com

Received:June 19,2015 | Published: May 30, 2017

\section{Introduction}

Disease and its cure has been the focus of research and discoveries ever since. Beginning around Imhotep (ancient Egyptian medicine - 2600BC), Charaka Samhita (objective methods of clinical examination -200BC) and Hippocrates (Natural causes of disease - 420BC) through Rhazes (first clear distinction between smallpox and measles-c.865 - 925) and Avicenna (the book of healing-1030) and again William Harvey (circulatory system - 1628), Claudius Aymand (first appendectomy-1736), down to Louis Pasteur and Robert Koch (germ theory of disease-1870), Alois Alzheimer (Alzheimer's disease - 1901), Frederick Banting (insulin-1921), Alexander Fleming (penicillin - 1928), Christian Barnard (first human heart transplant-1967), and top the present - Jacques Marescaux (Telesurgery-2001), kenneth Matsumura (Artificial Liver - 2001) ${ }^{1}$ and still counting. The data is insurmountable and so is the scientific work. The drive through the ages has been to free the human body and mind of disease which it doesn't acquire without reason. Over the centuries, various theories have been put forth on the causation of various disease processes. Interestingly, at any point of time the new propounded theory seems to make perfect sense. And then there is some more research and another theory seems like a perfect fit, yet again. We have been evolving. That should explain it well. We have evolved in our mental and physical capabilities over the centuries and so have the opportunities around us to learn.

The theory of natural causes and genetics as a causative factor for diseases has held us for most time. However recently the world is opening to a new third dimension to this continued discussion on "What affects our body and mind". This is the theory of Epigenetics.

In the recent years many convincing studies have been carried out by scientists from various fields- social, psychological, spiritual as well as Science. The sources are innumerable to quote. One of the most convincing to a modern logical mind is the study carried out by the celebrated Cell Biologist Bruce Lipton. His study on the cell membrane being the 'brain' of the cell leads to many a conclusion, the major one of them being: a. Biological behavior and gene activity are dynamically linked to the information from the environment.

b. It continues logically then that the control of our lives is not in the genetic roll of the dice at conception but in our hands. We can become the masters of our fate and not victim of genes.

Further on there have been many documented studies where in the deadliest of human diseases have been cured using techniques that free the body of harmful cellular memories blocked in the cells over the years. All these studies and their scientists are propagating non drug therapies and age old alternative therapies as treatment modalities for most diseases and there is a lot more pending in research. I base my suggestions on these studies and propose a preventive measure aiming at a healthy body- healthy mind for future generations.

\section{Method}

This being an Exploration study the method largely is the study of various research and study material available on relevant subjects. The observations are based on the data from various studies carried out around the world over the years. Also a lot of experience from a ten years period of my career as a counselor goes into forming the base study for this paper.

\section{Observations and discussion}

Most mental hygiene practitioner would agree that when a patient approaches with some apparent complaint, with some probing and after certain number of sessions, eventually everything points to some locus of unresolved emotions from the past. A history of trauma, betrayal, some hurt gone unnoticed, apparent or not, it is lurking in the dark past behind those tears, guilt, blame, fear, depression or any other present day complaint.

In many of these cases there are some associated long standing physical disorders like diabetes, hypertension, obesity or psychosomatic symptoms like dermatitis, gastrointestinal disturbances, migraine, respiratory illness, allergies etc. 
Medical practitioners come across many patients with chronic complaints that do not fully respond to the routine medical line of treatment or even if they do, return with frequent remission of their symptoms.

At the same time, the practitioners of alternative and complementary form of medicine are increasingly going on record with cases of remissions from acute and chronic symptoms. In many studies case of remission have been reported for illnesses for which classical medical science does not have a sure cure yet. The cases reported range from allergic dermatitis, un explained headaches to multiple sclerosis and even cancer.

There are always non- believers, but who believed that a body made of heavy metal can float in air and today air travel is as much a reality as travelling by rail or road. To add to this there is a huge amount of study on Past Life Regression therapy used for treatment of long standing so called idiopathic pains and other symptoms that show spontaneous remission following PLR sessions. Given the sheer number of such remissions reported and the research support available, we take it as a base for our present study.

\section{Scientific support}

Many of these studies from all over the world point out that the root cause of all illnesses lies in unhealthy Cellular memories. While previously it was believed that memory is the function of only brain cells, many recent evidences have pointed out that every cell in the body is a seat of memory.

\section{What is cellular memory?}

Cellular memory is defined as the concept that the cells in our body contain information about our personalities, tastes and histories. ${ }^{2}$ Evidence of this phenomenon has been found most prevalent in heart transplant recipients where in the recipients have shown strong preference for certain habits and foods after the transplant which they either disliked or had shown no interest in prior to the transplant. In many cases these newly acquired likes have been traced back to the donor. One such case that caught the attention of the world is that of Claire Sylvia, that was told through her book "A change of heart" after she received a heart and lung transplant. Since then many more such cases have been reported world over. Many studies have been conducted world over to probe in to the mystery of Cellular memory.

\section{Study reference I}

Candace Pert, former Chief of the Section of Brain Biochemistry of the Clinical Neuroscience Branch at the National Institute of Mental Health, studies health influences at the neuro-chemical level. She noted recently that "repressing emotions can only be causative of disease. Failure to find effective ways to express negative emotions causes you to "stew in your own juices." The key, according to Pert, is found in complex molecules called neuro-peptides. The brain contains about 60 different neuropeptides, including endorphins. These neuropeptides are the means by which all cells in the body communicate with each other. This includes brain-to-brain messages, brain-to-body messages, body-to-body messages, and body-to-brain messages thus transmitting the memory to the relevant cell. ${ }^{4}$

\section{Study reference 2}

New Danish Research has examined the mechanisms behind latent cell memory, which can come to life and cause previously nonexistent capacities suddenly to appear. Some yeast cells for example can abruptly change from being capable of switching between two sexual types. Research from the Niels Bohr Institute at the University of Copenhagen have used mathematical models and computer simulations to examine fundamental mechanisms of cellular memory. The research at the "Models of life basic research centre" at the Neils Bohr Institute has shown that communication between nucleosomes and positive feedback is likely to constitute a fundamental memory mechanism in individual cells. The mechanism gives both stability and openness to new influences which the cell could need to change state. Nature has a partner that controls the cells latent memory. ${ }^{5}$

\section{Study reference 3}

How Cellular Memory Might Work - It is thought that cellular memory might be possible since the discovery that neuropeptides exist not only in the brain as once thought but in all the tissues of the body. These neuropeptides are a way for the brain to "speak" to other bodily organs and for the organs to rely information back. ${ }^{6}$

\section{Study reference 4}

A study of American academy of experts in traumatic stress saysVirtually every behavioural pattern exhibited during routine activities of daily living results from learned data which is stored, or encoded, as cellular memory. Most of those behavioural patterns are benign, in that they do not contribute significantly to cellular destruction (i.e. disease). Some of those patterns, however, are expressed as significant reflections of traumatically encoded cellular information. In a condition such as Post Traumatic Stress Disorder, it must be kept in mind that the "problem" is an expression of traumatically encoded information at the cellular level. In order for therapy to have lasting effect, it is imperative that a primary focus of intervention involves isolation and decoding of the causative traumatic cellular memory pattern. It is becoming increasingly clear that the neurochemistry of emotion is a key factor that must be considered if any therapeutic intervention is to have lasting effect. All memory is encoded at the cellular level. Any mind-body procedure that beneficially alters destructive cellular memory patterns should be carefully evaluated as to its value in management of Post Traumatic Stress Disorders and other psychosomatic and/or psychological conditions. ${ }^{7}$

\section{Dr. Bruce lipton}

One of the important scientific interventions of our time comes from Dr. Bruce Lipton $(\mathrm{PhD})$. Dr. Lipton is a cell biologist by training. He taught Cell biology at the University of Wisconsin's School of Medicine and later performed pioneering studies at Stanford University's School of Medicine. The implications of his research shows that genes and DNA do not control our biology; but instead, DNA is controlled by signals from outside the cells, including the energetic messages emanating from our positive and negative thoughts.

\section{Study reference 5}

In his research, Dr. Lipton first went on to refute the age old theory that the DNA in the cell nucleus is the brain of the cell and that the DNA (genes) control our biology and its expression. An Experiment was designed to test the idea that the nucleus is the 'brain' of the cell. The results showed that following enucleation (removal of nucleus), many cells can survive for up to two or three months without genes. These cells actively ingest and metabolize food, maintain coordinated 
operation of their physiologic systems (respiration, digestion, excretion, motility etc.), retain an ability to communicate with other cells, and are able to engage in appropriate responses to growth and protection requiring environmental stimuli. ${ }^{8}$ These experiments on the enucleated cells go on to establish that the "nucleus" and in turn the "genes" are not the brain of the cell and do not control all that happens at the cell level except reproduction of lost proteins.

\section{Study reference 6}

Then intrigued by these results, Dr. Lipton went on to search the "real" brain of the nucleus and conducted numerous experiments on the Cell membrane. The conclusion, As Dr. Lipton put it "Cell membrane has numerous proteins which can be functionally classified as receptor proteins and effector proteins. The Receptor proteins are the cells sensory organs that respond to specific environmental stimuli. Some receptors monitor cells internal environment while the others monitor its external environment. Some receptors respond to physical signals while others respond to vibrational energy fields such as light, sound and radio frequencies... Thus Biological behaviour can be controlled by physical as well as invisible forces, including thought energy. ${ }^{9}$

\section{Study reference 7}

The receptors proteins however are not responsible for the behaviour of the cell on their own. While the receptor provides an awareness of the external signals, the Effector protein engages in an appropriate, life sustaining response. Together the receptor- effector complex acts as a switch, translating environmental signals into cellular behaviour. ${ }^{10}$

At the same time the theory of Epigenetics was propoundedEpigenetics literally means "Control above genetics". In the last decade, Epigenetic research has established that DNA blue prints passed down through genes are not set in concrete at birth. Genes are not destiny. Environmental influences, including nutrition, stress and emotions can modify those genes without changing their basic blue print. ${ }^{11}$ As if in furtherance to Dr. Lipton's study another interesting experiment was conducted by BA Cornell and associates.

\section{Study reference 8}

An isolated cell membrane was attached to a piece of gold foil under it. They then flooded the space between the two with a special electrolyte solution. When the membrane receptors were stimulated with complementary signal, the channels opened and allowed the electrolyte solution across the membrane. The foil served as a transducer, an electrical pick up device which converted the electrical activity into a digital read out on a screen. ${ }^{12}$ This study demonstrates that the cell membrane functions like a computer chip. These findings led to the formulation of important conclusions by Dr. Lipton:

\section{Insights from the above research}

a. Both computers and cells are programmable

b. The programmer lies outside the computer/cell. Biological behaviour and gene activity are dynamically linked to information from the environment, which is downloaded into the cell (via the receptor- effector mechanism). ${ }^{13}$

The whole organism: These studies were conducted on isolated single cells. However, a human being is a community of billions of these very single cells. The functions required for a single cell to stay alive are the same functions required by a community of cells to stay alive. But cells started to specialize when they formed multicellular organisms. In multi-cellular communities, there is a division of labour. For example, in a single cell, respiration is carried out by the mitochondria, in multi-cellular organism, the mitochondrial equivalent for respiration are the billions of specialized cells that form the lungs. Similarly, While it is the job of the cell membrane in a single cell to be aware of the environment, in our multi-cellular bodies those functions have been taken over by a specialized group of cells we call the nervous system. ${ }^{14}$

Evolution: As the organisms evolved, humans and other higher animals evolved a special region of the brain, the 'prefrontal cortex', a confluence of highly evolved cells that is associated with planning, decision making, thinking and forming a concept of 'self'. The learnings of this new brain are stored in other parts of the brain as the "subconscious". This "self" is also empowered to retrieve the memories from the other parts of the brain stored as the "subconscious" and thus make decisions for the present and future needs. However, as Dr. Lipton explains it, this especially "sharp" brain keeps learning from everything and anything in its environment. It does not stop to discern the "right' or 'wrong'.

Environment: Before we go ahead it is important to define what constitutes the Environment for us that influence our learning. The National Institute of open schooling, India, has this wholesome definition of environment. ${ }^{15}$ Environment is a very broad concept. Everything that affects us during our lifetime is collectively known as environment. The human-environment interaction has five major components. These components are briefly described below:

Physical environment: It includes aspect of natural environment such as climate, terrain, temperature, rainfall, flora, fauna, etc.

Social - cultural environment: It includes all aspects of cultural environment such as norms, customs, process of socialization, etc. It includes all the aspects dealing with other people and their creations.

Environmental orientations: It refers to the beliefs that people hold about their environment. For example, some people hold environment equivalent to God and therefore they perceive all its aspects with respect and reverence and try to maintain it in a perfect form and do not degrade it.

Environmental behavior: It refers to the use of environment by people in the course of social interactions. For example, considering the environment as personal space, where the individual identifies himself with it.

Products of behavior: These include the outcomes of people's actions such as homes, cities, dams, schools, etc. That is, these are products or outcomes dealing with the environment. Environment thus, is all that is outside and around us and has effect on us. Depending upon the environment and the formal and informal teachers around the growing individual, the data of the subconscious is formed. This data may not always be in sync with the requirements of the conscious individual at any particular point of time. eg. If as a child the individual has learned from his mother that all difficult situations are fearful and one to try to keep away, in adult life this same data from the subconscious would strongly influence the decision making ability of the person, irrespective of the fact that as an adult he may want to take big leaps.

The negative and limiting experiences of the childhood are growing because of the stressful environment that we live in today. A 
body of research suggests that our hyper- vigilant life style is severely impacting the health of our bodies. Our daily stressors are constantly activating the Hypothalamic- Pituitary axis priming our bodies for action. Unlike competitive athletes, the stressors in our bodies are not released from the pressures generated by our chronic fears and concerns. Almost every major illness that people acquire has been linked to chronic stress. ${ }^{16-19}$

Tracing back, thus, it can be seen that though we behave and act as a single organism, everything happens at the level of single cells that form their own memories with every environmental influence. Applying this collective data to the theory of causation of most illnesses, it can be implied that most of the illnesses and disorders that we suffer from, have an environmental reason that when not intercepted in time leads to accumulation of harmful cellular memories, eventually progressing into a disease form. Studies have pointed out that only $5 \%$ of cancer and cardiovascular patients can attribute their disease to heredity ${ }^{20}$ and that the malignancies in a significant number of cancer patients are derived from environmentally induced epigenetic alterations and not defective genes. ${ }^{21-24}$

Memory formation process: Interestingly, the process of learning from the environment and forming subconscious memories starts as early as soon after the conception of the child.

\section{Study reference 9}

The effect of environment or the epigenetics plays a strong role even before the child is born. "The quality of life in the womb, our temporary home before we are born, programs our susceptibility to coronary artery disease, stroke, diabetes, obesity and a multitude of other conditions in the later life. ${ }^{25}$

\section{Study reference 10}

Recently even wider range of adult related chronic disorders including osteoporosis, mood disorders and psychoses have been intimately linked to pre and peri-natal developmental influences. ${ }^{26}$

\section{Study reference I I}

In the same note, this epigenetic environment can go awry and lead to an array of chronic disorders in older age if an individual experiences adverse nutritional and environmental circumstances during fetal and neonatal periods of development. ${ }^{27}$

The cross road: The believers in modern medicine and specially the Pharma industry are not very open to these new theories of disease development. Their focus is on coming up with new drugs every time a new theory is brought forth. For obvious reasons that the industry is the one most benefited by the illnesses of the population. However, it is imperative to look into the following data.

\section{Study reference 12}

According to conservative estimates published in the journal of American Medical Association, iatrogenic illness (illnesses resulting from medical treatment) is the third- leading cause of death in America. More than 120000 people die from adverse effects of prescribed drugs every year. ${ }^{28}$ A newer study came up with even more dismal figures. That study concludes that iatrogenic illness is actually the leading cause of death in the United States and the adverse reactions to prescription drugs are responsible for more than 300,000 deaths in a year. $^{29}$
Current study: The current study is based on this data.

a. Every individual is made of billions of small cells each having a capacity to develop a memory of its own derived from the environmental influences.

b. Biological behaviour and gene activity are dynamically linked to information from the environment, which is downloaded into the cell (via the receptor- effector mechanism).

c. That environmental information, and not genes, controls the key to the process of disease formation.

d. This information transmitting process can be voluntarily controlled/changed to quite a good extent.

e. Once the disease is caused the damage is not just physical, rather psychological, financial and social too, hence the target of health has to be Prevention.

Recommendations: This study is in favour of putting more efforts in the PREVENTION of the disease process and it recommends.
a. Interception at the earliest age.
b. Use of supplementary and Complementary education.
c. Why interception at the earliest age.

\section{Study reference 13}

Between birth and two years of age, the human brain predominantly operates at the lowest EEG frequency, 05-4 cycles/sec (Hz), known as delta wave. A child begins to spend more time at a higher level of EEG activity characterized as theta $(4-8 \mathrm{~Hz})$ between 2 and six years of age. ${ }^{30,31}$ Hypnotherapists drop their patients' brain activity into delta and theta because these low frequency brain waves put them into a more suggestible, programmable state. This gives us an important clue as to how children, whose brains are most operating at the same frequencies between birth and six years of age, can download the incredible volume of information they need to thrive in their environment.

\section{Why use of education as a means to prevention?}

a. The health of the cell and thus the individual is influenced by the environmental factors.

b. These environmental stimuli can be controlled/ changes by conscious awareness of the individual, thus processing the environmental stimuli positively, with an attempt to storing positive and healthy cell memories. Some supporting evidence comes from this data:

\section{Study reference 14}

The promise for cancer prevention is derived from observational epidemiologic studies that show associations between modifiable lifestyle factors or environmental exposures and specific cancers ${ }^{32}$

\section{Study reference 15}

Obesity is one of the greatest public health challenges of the $21 \mathrm{st}$ century. Its prevalence has tripled in many countries of the WHO European Region since the 1980 s, and the numbers of those affected continue to rise at an alarming rate, particularly among children. In addition to causing various physical disabilities and psychological 
problems, excess weight drastically increases a person's risk of developing a number of non-communicable diseases (NCDs), including cardiovascular disease, cancer and diabetes. The risk of developing more than one of these diseases (co-morbidity) also increases with increasing body weight. Obesity is already responsible for $2-8 \%$ of health costs and $10-13 \%$ of deaths in different parts of the Region. ${ }^{33}$

\section{Study reference 16}

The rising epidemic of obesity reflects the profound changes in society and in the behavioral patterns of communities although many individuals may become obese, because they have a genetic or other biological predisposition to gain weight more readily when they are exposed to an unfavourable environment ${ }^{34}$

\section{Study reference 17}

The Consultation concluded that global epidemic projections for the next decade are so serious that public health action is urgently required. It is thus essential to develop new preventive public health strategies which affect the entire society. Without societal changes, a substantial and steadily rising proportion of adults will succumb to the medical complications of obesity. ${ }^{35}$

\section{Study reference 18}

In the immediate term, the principal causes of lung and numerous other cancers are amenable to change through behavioral and policy/ environmental interventions, which offer best chance of substantially reducing cancer burden. ${ }^{36}$

\section{Study reference 19}

The President's Cancer Panel recently released a report that summarized the findings of four meetings convened between September 26, 2006, and February 27, 2007, to discuss behaviors that affect cancer risk. The panel's report commented that most of the federally sponsored cancer prevention research emphasizes genetic and other biologic factors, but this important work needs to be accompanied by research that addresses the macro-environment and the physical, social, and cultural contexts in which food choices, physical activity, and tobacco use occur. ${ }^{36}$

\section{Study reference 20}

There are well agreed upon standards for basic nutrition and minimum levels of physical activity for sustaining good health. However, much less is known how to effectively encourage people to make healthy choices. ${ }^{37}$ Once again referring back to our data it is concluded that:

a. The environment controls Our Biology.

b. We have the choice to control as to what extent we let the environment influence us and it which way.

And yet, as adults we make the wrong choices every day. The reason for those wrong choices comes from our data: How much so ever we would want something better in life, the data in our subconscious rules supreme is deciding our actions, reactions and behaviors based on out learning since childhood.

Here we come to the most important conclusion of the study: What goes in the subconscious and what forms our memories over a period of our life time, is the key to making healthy choices towards a healthy life. The recommendations are based on this conclusion.

\section{Interventions in childhood}

A child attends three major institutions for education in life:
a. Home
b. Society
c. School

The Intervention towards prevention of disease and promoting a healthy life has to be done at all these three levels. The changes/ additions in the education that are recommended are:

\section{Encourage conscious teaching}

Referring to our data that says that our environmental educators feed us with a huge data that forms a subconscious database for the future choices we make, it is recommended that the most prominent educators in our environment, i.e. the parents and teachers be trained for consciously delivering important life skill lessons mentioned below, to the young people.

\section{Training on decision making and conflict handling}

From early in life the child has to be given opportunities to make decisions regarding himself and taught to understand the consequences. The conflicts in his small world should be taken as teaching - learning opportunity, and he has to be taught to handle it in an amicable way, During these process of teaching decision making and conflict handling, the child must not be shielded from the emotional pain, rather it should be taken as an opportunity to help him learn the consequences of his action in a guided manner.

\section{Handling emotions positively}

Talking to the children since the early age about their emotions and helping them express themselves using precise words like sad, hurt, insulted, hungry, happy, satisfied, guilty, fearful, envious etc will teach them to handle emotions in the right way by expressing them correctly, not covering up with tantrums and most importantly not to keep the emotions buried inside to avoid formation of unhealthy memories.

\section{Creating self awareness and self esteem}

Our society does not encourage any focus on self. The concepts of self of the child are formed on the feedback from those in his immediate environment, and this may not always be positive. Thus most adults are not comfortable addressing any issues about self. The child must be encouraged to understand himself, his personality, his individuality, his unique presence in this world and must be taught to respect himself for what he is. He must be taught about competition with self for positive development and to respect the difference from others. This would give the child the strength and confidence needed to handle stress in the outside world full of competition and uncertainty.

\section{Imbibing concepts of independence and interdependence}

Importance of both these modes of existences of man have to be consciously taught to the child. Independence, so that he respects himself and can stand up for himself when things are not favourable. Interdependence, because he has to learn to form a peaceful coexistence with others in the society for his growth and the progress of his society. 


\section{Training on self discipline and priority management}

Every child resists the discipline that comes from others. Giving him the opportunity to decide his priorities by gentle guiding and being responsible for his choices and more over not shielding him from the consequences of falling out would make him responsible for making the healthy choices in life and also desist him from learning the blame game.

\section{Teaching about empathy and social tolerance}

Much of our stress in adult life arises from intolerance for the other. Learning in early life that every individual is different and has as much right to his/her opinion and choices would help the child to grow into a healthy adult ready to give space to others and avoid the stress created otherwise.

\section{Relationship management}

Relationships form the basis of human existence. All the happiness as well as stress creating situations arise out of the handling of relationships. The Children should be made aware that the relationships are not to be taken for granted and special care has to go into maintaining every relationship in life.

\section{Spiritual education for mind - body alignment}

Spirituality in early life opens the child to a world beyond materialism. This creates a place of solace for him when he enters the rat race and helps him handle stressful situations in balanced way.

\section{Intervention for adults}

This educational intervention for the adults is essential to create a positive learning environment for the children as much as it is needed for attempt towards drug free positive health.

a. Parenting Education - In consensus with the research findings on the effect of environment on a child in the womb, it is essential to include both the parents in early education at or before conception on how to create the right learning environment for the expected child.

b. Self awareness and esteem building - Most of the adults suffer from the wrong learning as a child where he/ she had been repeatedly, though unknowingly told that he was "good for nothing" or "useless" or simply "less than others". These messages form negative memories that prompt unhealthy practices of handing everyday life conflicts and situations. A conscious unlearning of these negative memories followed by positive training for creating a new set of healthy memories has to be added.

c. Positive stress management techniques.

d. Spiritual awareness in the materialistic environment.

e. Awareness about spiritual role of parents as the bearers of new souls on this earth and their responsibilities thereof.

\section{Conclusion}

With the advance of the century, health and healthy life style is the major concern of all nations. We as responsible scientific community cannot let a handful of Pharma giants kidnap us from the natural ways towards positive health. Our children, the children of the future are our responsibility. We owe it to them to bring them up in an environment that does not reek of ill-health and artificial drugs. The dynamic environment around us can be challenging in so many ways and expose us to new disease forming threats over and again. Since now that we are equipped with the understanding of the formation of physical and psychological disease process, we should embark on the safe, easy, cheap and self controlled way to a healthy life- and that is Prevention. "Positive health is natural, all it needs is the understanding and right education".

\section{Acknowledgements}

None.

\section{Conflict of interest}

The author declares no conflict of interest.

\section{References}

1. http://en.wikipedia.org/wiki/Timeline of medicine and medical technology

2. Robert Todd Carroll. Cellular Memory. The Skeptics Dictionary. 1994.

3. Claire Sylvia, William Novak. A Change of Heart. Little, Brown and Company, Boston, USA; 1997. 237 p.

4. http://www.cellularmemory.org/about/about_cellularmemory.html

5. IB Dodd, MA Micheelsen, K Sneppen, et al. Theoretical Analysis of Epigenetic Cell Memory by Nucleosome Modification. Cell. 2007;129:813-822.

6. Inherited Memory in Organ Transplant Recipients.

7. Thomas R. McClaskey. Decoding Traumatic Memory Patterns at the Cellular Level. The American Academy of Experts in Traumatic Stress. 1998.

8. Bruce Lipton. The Biology of Belief, Unleashing the power of Consciousness, Mater and Miracle. India: Hay House Publication; 2010. 35 $\mathrm{p}$

9. Bruce Lipton. The Biology of Belief, Unleashing the power of Consciousness, Mater and Miracle. India: Hay House Publication; 2010. 53 p.

10. Bruce Lipton. The Biology of Belief, Unleashing the power of Consciousness, Mater and Miracle. India: Hay House Publication; 2010. 54 p.

11. Leslie Pray, Silverman PH. Epigenetics: Genome meet your environment. Rethinking Genetic Determinism: Wiyh only 30000 genes, what is it that makes humans human? The Scientist. 2004;32-33.

12. Cornell BA, Braach Maksvytis VL, King LG, et al. A biosensor that uses ion-channel switches. Nature. 1997;387(6633):580-583.

13. Bruce Lipton. The Biology of Belief, Unleashing the power of Consciousness, Mater and Miracle. India: Hay House Publication; 2010. 61 p.

14. Bruce Lipton. The Biology of Belief, Unleashing the power of Consciousness, Mater and Miracle. India: Hay House Publication; 2010. 58 p.

15. http://www.nios.ac.in/srsec328newE/328EL23.pdf

16. Segerstrom SC, GE Miller. Psychological stress and human immune system: a meta-analytic study of 30 years of inquiry. Psychol Bull. 2004;130(4):601-630. 
17. Kopp MS, Réthelyi J. Where psychology meets psychology: Chronic stress and premature mortality-the Central Eastern European health paradox. Brain Res Bull. 2004;62(5):351-367.

18. Bruce McEwen, Elizabeth N Lasley. The end of stress as we know it. USA: National Academic Press; 2002.

19. McEwen BS, T Seeman. Protective and damaging effects of mediators of stress: Elaborating and testing the concepts of Allostatis and Allostatic load. Ann N Y Acad Sci. 1999;896:30-47.

20. Willett WC. Balancing life styles and Genomic research for disease prevention. Science. 2002;296(5568):695-698.

21. Jim Kling. Put the blame on Methylation. The Scientist. 2003;27-28.

22. Peter A Jones. Death and Methylation. Nature. 2001;409:141-144.

23. Nathan Seppa. Silencing the BRCA $\mathrm{B}_{1}$ gene spells trouble. Science News. 2000;157(16):247.

24. Stephen B. Baylin. Tying it all together: Epigenetics, Genetics, Cell cycle and Cancer. Science. 1997;277(5334):1948-1949.

25. Nathanielsz PW. Life in the womb: the origin of health and disease. Ithaca, NY: Promethean Press; 1999.

26. Gluckman PD, Hanson MA. Living with the past: Evolution, development and patterns of disease. Science. 2004;305(5691):1733-1736.

27. Bateson P, Barker D, Clutton-Brock T, et al. Developmental Plasticity and human health. Nature. 2004;430(6998):419-421.
28. Starfield B. Is US health really the best in the world? JAMA. 2000;284(4):483-485.

29. Gary Null, Carolyn Dean, Martin Feldman, et al. Death by Medicine. Nutrition Institute of America, New York, USA; 2003.

30. Laibow R. Clinical Applications: Medical applications of Neurofeedba$c k$. Introduction to quantitative EEG and Neurofeedback. 2nd ed. In: JR Evans, A Aberbanel, et al. Editors. Burlington: Academic Press; 1999. $528 \mathrm{p}$.

31. Laibow R. Personal Communication with BH Lipton. New Jersey, USA; 2002.

32. Cancer Prevention Overview (PDQ $\left.{ }^{\circledR}\right)$-Health Professional Version.

33. Obesity. 1980.

34. Obesity: Preventing and managing the Global Epidemic. Report of a WHO Consultation on Obesity. World Health Organ Tech Rep Ser. 2000;894 p.

35. Suzanne H Reuben. Promoting Healthy Lifestyles 2006-2007. Annual Report of the President's Cancer Panel. USA, 2007. 185 p.

36. F as in Fat: How Obesity Policies are falling in America. Trust for America's Health, USA; 2007.

37. Bruce Lipton. The Biology of Belief, Unleashing the power of Consciousness, Mater and Miracle. India: Hay House Publication; 2010. 